AS WE SEE IT

\title{
Acclimatization in tropical reef corals
}

\author{
Peter J. Edmunds ${ }^{1, *}$, Ruth D. Gates ${ }^{2}$ \\ ${ }^{1}$ Department of Biology, California State University, 18111 Nordhoff Street, Northridge, California 91330-8303, USA \\ ${ }^{2}$ University of Hawaii, School of Ocean and Earth Science and Technology, Hawaii Institute of Marine Biology, PO Box 1346,
} Hawaii 96744, USA

\begin{abstract}
Global climate change (GCC) is the most widespread environmental peril facing tropical coral reefs, yet the capacity of scleractinian corals to survive the challenge is not well understood. Acclimatization is a primary mechanism by which organisms match their physiology in a timely and beneficial way to a rapidly changing environment, and so it is not surprising that the question 'can corals acclimatize to GCC effects?' is a central theme in coral reef science today. Here, we argue that acclimatization in corals, as in all organisms, is axiomatic-i.e. evident without proof or argumentand that the emphasis on whether corals can acclimatize to GCC is distracting. The key to understanding how corals will respond to future environmental challenges lies in understanding the extent to which acclimatization is important. This is a subject that has received great attention in other systems, and we think that coral biologists can benefit from a deeper understanding of the classical physiological expression of acclimatization, and a broader appreciation of the experimental designs that are required for elucidating the complex relationships among physiology, physical conditions, and recent history.
\end{abstract}

KEY WORDS: Coral $\cdot$ Scleractinia $\cdot$ Acclimatization $\cdot$ Climate change

\section{Introduction}

By most measures, the percentage cover of scleractinian corals on many tropical reefs has been declining for decades (Gardner et al. 2003, Bellwood et al. 2004). These changes have been caused by diverse agents (e.g. Bellwood et al. 2004), but the most severe and geographically widespread losses have been attributed to rising seawater temperature associated with global climate change (GCC) (Hoegh-Guldberg 1999, Bruno \& Selig 2007). High temperature kills corals primarily through bleaching, in a process that is exacerbated by high light intensities (Jones et al. 1998) and, indirectly, by pathogens (Selig et al. 2006). In the coming decades, the thermal consequences of GCC will intensify (IPCC 2007), and this, combined with ocean acidification resulting from high levels of atmospheric $\mathrm{CO}_{2}$, will have serious effects on corals (HoeghGuldberg et al. 2007).

\section{Adaptation versus acclimatization}

The geological history of scleractinians reveals that they have displayed strong patterns of resistance to environmental stress (Buddemeier \& Smith 1999), and we infer that they have the potential to adapt to the current suite of environmental challenges, via changes in the genetic composition of the populations through natural selection, to favor reproductive success under the prevailing conditions. Nevertheless, the recent short-term record tells a different story of sensitivity to environmental degradation, and therefore a 'biogeoparadox' exists between the short- and long-term history of coral reefs (Buddemeier \& Smith 1999). For contemporary reefs, the consensus among many scientists is that the tempo of evolutionary transformation within the Scleractinia will be inadequate for responding to GCC (Hoegh-Guldberg et al. 2007), which is changing the environment at an unprecedented rate 
(IPCC 2007). Assuming that most scleractinians are incapable of genetic adaptation (as defined above) to the rapid changes resulting from GCC, the alternative response will be genotype-independent phenotypic changes, which are classically described as acclimatization (Prosser 1991) but can effectively be subsumed into the framework of phenotypic plasticity (Huey \& Berrigan 1996). Acclimatization refers to phenotypic changes occurring under naturally varying conditions, but when these changes are investigated experimentally by manipulating a single environmental factor, the responses are termed acclimation (Prosser 1991). Acclimatization is not functionally equivalent to acclimation, however; when the response is caused by several agents, as occurs in nature, the role of each agent is unclear, as is the extent to which their cumulative effect is equivalent to the sum of their isolated effects.

Phenotypic plasticity and acclimatization have been favorite subjects of investigation in corals for decades (Coles \& Jokiel 1978, Foster 1979), and such studies have in general embraced simple experimental approaches employing factorial combinations of a few treatments, or reciprocal transplantation among a handful of sites. The majority of corals are, however, strongly influenced by mutualistic symbioses with a variety of taxa, the best known of which are dinoflagellates of the genus Symbiodinium (Muller-Parker \& D'Elia 1997). Such associations create a rich context for potentially beneficial responses to environmental variation (Moran 2007). Importantly, because natural selection acts on biological units whose parts function in a coordinated manner and are responsive to environmental change (Mayr 1997, Gould \& Lloyd 1999), genotypic responses attributed to the coral host or their symbiotic partners can be described as adaptation (e.g. Moran 2007). For tropical scleractinians, the high genetic diversity in Symbiodinium (Apprill \& Gates 2007), which was unimaginable 2 decades ago (Blank \& Trench 1985), has fueled a debate evaluating the role of symbiont 'switching' and 'shuffling' as a means to respond (i.e. adapt) in beneficial ways to GCC (Buddemeier et al. 2004). While agreement has yet to be reached regarding the importance of this means of adaptation, there is already extensive evidence for 'traditional' acclimatization in the scleractinia, mostly in response to variation in temperature and light (Coles \& Jokiel 1978, Falkowski \& Dubinsky 1981).

\section{Physiological basis of acclimatization}

In Gates \& Edmunds (1999) we argued that there is no reason to suppose that scleractinians will differ from other eukaryotes in their capacity for physiological acclimatization - presumably through changes in the genetic expression of macromolecules, differential use of existing macromolecules, or modifications to the internal milieu within which macromolecules operate (Hochachka \& Somero 2002)-and we reemphasize this assertion here. Nevertheless, analyses addressing whether corals can acclimatize to GCC are still common. Where coral acclimatization has been studied, 3 problems are frequently encountered: (1) the research is often equivocal with regard to the operational definition of the process (acclimation, acclimatization, or adaptation) under investigation, or the environmental factor to which it is responding; (2) the interpretation of the results falls foul of the 'adaptationist program' (Gould \& Lewontin 1979) by assuming (without testing) that acclimatization is beneficial (Huey \& Berrigan 1996); (3) the experimental design and statistical analysis often have limited ability to address the question under study. Importantly, there are substantial differences in the design of studies aimed at evaluating whether corals can acclimatize to GCC, versus those determining the role(s) played by acclimatization. For example, the former design assumes that acclimatization may be absent (which we contend is inconceivable), and the latter assumes that the experimental design is suitable to statistically detect acclimatization in its various forms (Figs. 1 \& 2), which may not be the case.

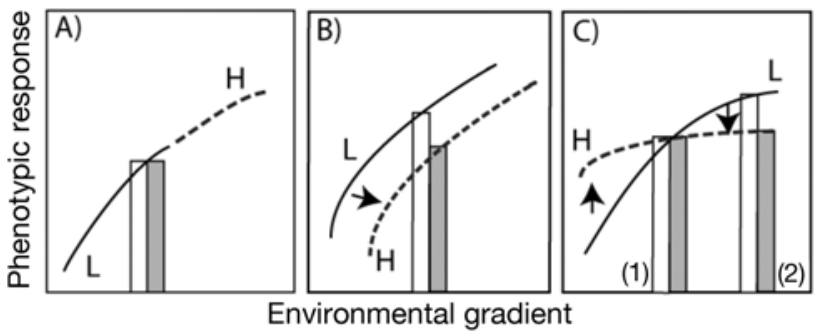

Fig. 1. Reaction norms for phenotypic responses against continuously distributed environmental conditions for corals maintained under high $(\mathrm{H}$, dashed line) or low ( $\mathrm{L}$, solid line) levels of an environmental condition. Vertical bars display the phenotypic response at a single value of the environmental gradient for corals maintained initially at high (open) or low (shaded) levels of the gradient in a factorial experiment designed to test for acclimation. (A) No acclimation occurs as a result of $\mathrm{H}$ or $\mathrm{L}$ conditions, and the relationship is described by a single curvilinear response; (B) acclimation occurs as a result of $\mathrm{H}$ and $\mathrm{L}$ conditions, with the response translated (arrow) along the abscissa (the shape of the response does not change); (C) acclimation occurs as a result of $\mathrm{H}$ and $\mathrm{L}$ conditions, with the response rotated (arrows), such that the shape of the response changes; rotation can also be combined with translation. Factorial experiments with categorical treatments would correctly reveal no acclimation in (A), but acclimation in (B). For (C), the outcome would depend on where along the environmental gradient (i.e. Scenario 1 or 2) the categorical treatments occurred (graphs modified from Prosser 1991) 
The work of Brown et al. (2002) provides an elegant example of a factorial study of acclimatization in corals, demonstrating that an initial exposure to high light and aerial conditions subsequently reduced the effects of high temperature; acclimatization was interpreted to be beneficial. In other studies of acclimatization in corals, a variety of physical conditions have been used to analyze the response of several traits, but the conceptual approach remains similar to that of Brown et al. (2002). Significantly, such factorial designs do not span the physical gradient necessary to capture the potential curvilinear relationship between a given trait and the environmental conditions to which it is responding. Consequently, factorial studies of acclimatization have limited capacity to distinguish among competing hypotheses regarding the mechanistic basis of the response, namely those resulting in shifts in the curvilinear phenotype-environment relationship that can be described as translation (a lateral shift of the relationship on the phenotype-environment plot), rotation (an angular shift in the relationship about a fixed point), or translation-rotation (an angular shift combined with a lateral shift in the relationship) (Fig. 1) (after Prosser 1991). Further, although factorial studies have been successful at detecting acclimatization (Fig. 1B) (Brown et al. 2002), a negative result can have multiple interpretations, only one of which is that

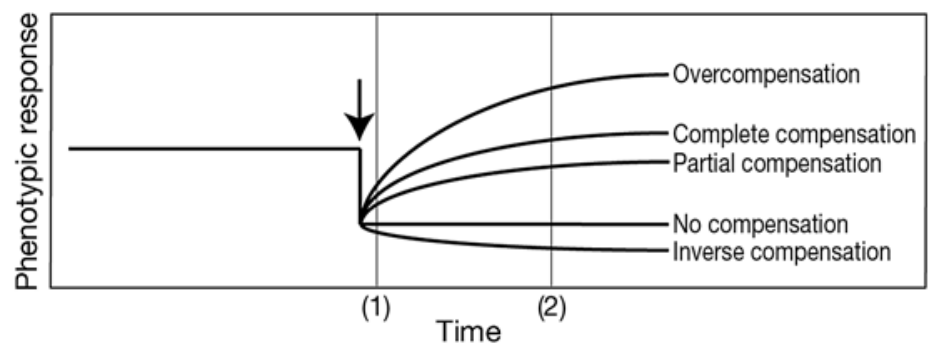

Fig. 2. Range of phenotypic outcomes as a function of time following a change in conditions (arrow) that altered the phenotype; a depression of the phenotype is shown, but the direction of change is irrelevant. In this diagram, acclimation subsequent to the perturbation can result in any of 5 possible responses, 4 of which satisfy the criteria of acclimation. Overcompensation: the phenotype exceeds the initial value; complete compensation: return to initial value; partial compensation: incomplete return to initial value; no compensation: absence of acclimation; inverse compensation: decline relative to the initial value. Any one of these 5 outcomes could have beneficial value, depending on the circumstance, although complete compensation often is construed as 'full' acclimation. In the context of corals and their response to GCC, manipulative experiments of varying duration (Time 1 vs. Time 2) following the imposition of environmental stress, would yield differing answers with regard to the roles of acclimation. Moreover, a factorial experimental design with initial and final sampling would be unable to resolve the Treatment $\times$ Time interactions that are required to discriminate among the possible acclimation responses (graph modified from Huey \& Berrigan 1996) acclimatization did not occur (Fig. 1C). Lastly, factorial studies of coral acclimatization typically are divorced from knowledge of the temporal and directional structure of the phenotypic responses to environmental change (Fig. 2), although we suspect that the expectation that acclimatization (should it occur) will be fully compensatory (Fig. 2), is pervasive. There are 2 important consequences of these oversights: (1) The outcome of factorial acclimatization experiments can differ, depending on their duration (e.g. Fig. 2, Time 1 versus Time 2). (2) The statistical framework appropriate for a factorial design will probably be insufficient to resolve the Treatment $\times$ Time interaction or the direction of phenotypic responses, both of which are important in distinguishing the differing types of acclimation (Fig. 2).

\section{Further studies of acclimatization in reef corals}

The concepts embodied in Figs. 1 \& 2 have been entrenched in the classic physiological literature for decades, but there is a tendency for these principles to be overlooked by coral biologists rushing to answer what at first glance might seem to be a simple question: Can corals acclimatize to resist GCC? The answer is likely to be complex, and will not be elucidated with simple experimental designs. We do not dispute the findings of recent studies that have demonstrated acclimatization in corals, in part because these responses are characteristic of virtually all eukaryotes (Gates \& Edmunds 1999). However, we feel that the mechanisms underlying acclimatization in corals are likely to encompass a level of sophistication and complexity that is currently unappreciated and that will only be unveiled in studies specifically designed to address these details. An improved understanding of acclimatization responses in corals is fundamental to defining the biological traits and mechanisms that are linked with survivorship in corals, and it is this line of discovery that will ultimately enhance our capacity to address the simple question 'How will corals respond to GCC?'

Acknowledgements. This research was supported in part by grants OCE 04-17412 and DEB 03-43570 from the National Science Foundation, and is a contribution of the Moorea Coral Reef (MCR) LTER Site. We thank our colleagues and students who knowingly or unwittingly contributed to the ideas expressed in this paper, for which of course, we take full responsibility. This is contribution no. 149 of the Marine Biology Program of California State University, Northridge, and no. 1314 of the Hawaii Institute of Marine Biology. 


\section{LITERATURE CITED}

Apprill AM, Gates RD (2007) Recognizing diversity in coral symbiotic dinoflagellate communities. Mol Ecol 16: $1127-1134$

Bellwood DR, Hughes TP, Folke C, Nystrom M (2004) Confronting the coral reef crisis. Nature 429:827-833

Blank RJ, Trench RK (1985) Speciation and symbiotic dinoflagellates. Science 229:656-658

Brown BE, Dunne RP, Goodson MS, Douglas AE (2002) Experience shapes the susceptibility of a reef coral to bleaching. Coral Reefs 21:119-126

Bruno JF, Selig ER (2007) Regional decline of coral cover in the Indo-Pacific: timing, extent, and subregional comparisons. PLoS One 8:1-8

Buddemeier RW, Smith SV (1999) Coral adaptation and acclimatization: a most ingenious paradox. Am Zool 39: $1-9$

Buddemeier RW, Kleypas JA, Aronson RB (2004) Coral reefs and global climate change. Pew Center on Global Climate Change, Arlington, VA

Coles SL, Jokiel PL (1978) Synergistic effects of temperature, salinity and light on the hermatypic coral Montipora verrucosa. Mar Biol 49:187-195

Falkowski PG, Dubinsky Z (1981) Light-shade adaptation of Stylophora pistillata, a hermatypic coral from the Gulf of Eilat. Nature 289:172-174

Foster AB (1979) Phenotypic plasticity in the reef corals Montastraea annularia (Ellis \& Solander) and Siderastrea siderea (Ellis \& Solander). J Exp Mar Biol Ecol 39:25-54

Gardner TA, Cote IM, Gill JA, Grant A, Watkinson AR (2003) Long-term, region-wide declines in Caribbean corals. Science 301:958-960

Gates RD, Edmunds PJ (1999) The physiological mechanisms of acclimatization in tropical reef corals. Am Zool 39:30-43

> Gould SJ, Lewontin RC (1979) The spandrels of San Marco and the Panglossian paradigm: a critique of the adaptationist programme. Proc R Soc Lond B Biol Sci 205: 581-598

Gould SJ, Lloyd EA (1999) Individuality and adaptation

Editorial responsibility: Matthias Seaman,

Oldendorf/Luhe, Germany across levels of selection: how shall we name and generalize the unit of Darwinism? Proc Natl Acad Sci USA 96: 11904-11909

Hochachka PW, Somero GN (2002) Biochemical adaptations. Oxford University Press, Oxford

- Hoegh-Guldberg O (1999) Climate change, coral bleaching and the future of the world's coral reefs. Mar Freshw Res 50:839-866

$>$ Hoegh-Guldberg O, Mumby PJ, Hooten AJ, Steneck RS and others (2007) Coral reefs under rapid climate change and ocean acidification. Science 318:1737-1742

Huey RB, Berrigan D (1996) Testing evolutionary hypotheses of acclimation. In: Johnston A, Bennett AF (eds) Phenotypic and evolutionary adaptation to temperature. Cambridge University Press, Cambridge, p 205-237

IPCC (Intergovernmental Panel on Climate Change) (2007) Climate change 2007. Working Group I report: the physical science basis. Cambridge University Press, Cambridge

Jones RJ, Hoegh-Guldberg O, Larkum AWD, Shreiber U (1998) Temperature-induced bleaching of corals begins with impairment of the $\mathrm{CO}_{2}$ fixation mechanism in zooxanthellae. Plant Cell Environ 21:1219-1230

Mayr E (1997) The objects of selection. Proc Natl Acad Sci USA 94:2091-2094

Moran NA (2007) Symbiosis as an adaptive process and source of phenotypic complexity. Proc Natl Acad Sci USA 104:8627-8633

Muller-Parker G, D'Elia CF (1997) Interactions between corals and their symbiotic algae. In: Birkeland C (ed) Life and death of coral reefs. Chapman \& Hall, New York, p 96-113

Prosser CL (1991) Environmental and metabolic animal physiology. Wiley-Liss, New York

Selig ER, Harvell CD, Bruno JF, Willis BL, Page CA, Casey KS, Sweatman H (2006) Analyzing the relationship between ocean temperature anomalies and coral disease outbreaks at broad spatial scales. In: Phinney JT, HoeghGuldberg O, Kleypas J, Skirving W, Strong A (eds) Coral reefs and climate change: science and management. American Geophysical Union, Washington, DC, p 111-128

Submitted: May 6, 2008; Accepted: May 9, 2008

Proofs received from author(s): May 15, 2008 